Original article

https://www.journal-imab-bg.org

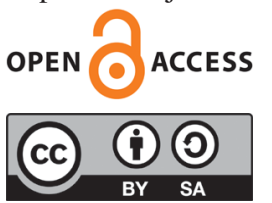

\section{APPROBATING REDUCTION OF BODY FAT CRYOLIPOLYSIS AND CAVITATION \\ FOR WITH}

\author{
Mariya Gramatikova ${ }^{1}$, Stamenka Mitova $^{1}$, Iliya Kanelov ${ }^{2}$ \\ 1) Department Kinesitherapy, Faculty of Public Health, Healthcare and Sports, \\ South-West University "Neofit Rilski”, Blagoevgrad, Bulgaria \\ 2) Department Theory and methodology of physical education, Faculty of \\ Pedagogy, South-West University "Neofit Rilski”, Blagoevgrad, Bulgaria.
}

\section{SUMMARY}

The aim of this study is to develop and approbation methods and algorithms for reducing body fat.

Material/Methods: In the research, participants were aged 35-45 years with obesity. Anthropometric parameters were analyzed with an impedance analyzer for bodyweight parameters, a somatotype profile, by the methodology Heath-Carter. Measurements were made before and after 60 days of the apparatus physiotherapy including cryolipolysis and cavitation. Twice a week a cardio training was performed

Results: The somatotype of the contingent is Mesomorphic - endomorphic endomorphism is highest (6.63), and mesomorphic (6.36) is higher than ectomorph (1.08). In the second study, the data showed a decrease in the endomorphic index $(6,18)$, having almost equalized values with the mesomorph $(6,15)$, while at the same time the greatest movement was observed in the ectomorphic index, which increased with nearly $30 \%$ to 1.38 . The research contingent has positively influenced the procedures and its propensity for weight loss has increased. However, the somatotype profile remains a mesomorph-endomorph. From the data on the quality of the body composition, only the BMI $(\mathrm{kg} / \mathrm{m} 2)$, VFA $(\mathrm{cm} 2)$ and MBF $(\mathrm{kg})$ parameters have statistically significant decreases. The measured parameters before and after the applied procedures, with no statistically reliable changes $\mathrm{P}$-value $<0.05$ level (Wilcoxon, t-test) observed only in the circumference of the hips. A statistically significant decrease of the results is found in the circumferences of both thighs at the measured heights P-value $<0.0001$ level (Wilcoxon, t-test).

Conclusion: The approbation methodology for reducing body fat has a positive effect on the contingents and leads to the modeling of the body.

Keywords: physiotherapy, obesity, BMI, somatotype, body contouring, cavitation, cryolipolysis

\section{INTRODUCTION}

In the United States of America, it is estimated that obesity causes an additional 111909 to 365000 deaths a year, while overweight in Europe accounts for 1 million
(7.7\%) of deaths. Obesity reduces life expectancy by an average of six to seven years: BMI of 30-35 reduces life expectancy by two to four years, while severe obesity (BMI> 40) reduces life expectancy by 10 years. Obesity increases the risk of many physical and mental illnesses. These concomitant diseases most commonly occur in metabolic syndrome, a combination of disease states that includes type 2 diabetes mellitus, high blood pressure, hypertension and ischemic heart disease, osteoarthritis, high blood cholesterol levels, and high triglyceride levels [1, 2, 3, 4, 5].

The World Health Organization (WHO) predicts that overweight and obesity can soon replace more traditional public health problems such as malnutrition and infectious diseases as the most important cause of poor health [6, 7]. The latest epidemiological data from the WHO (2014) show that more than 1.9 billion adults over 18 are overweight $(39 \%)$ and over 600 million have obesity (13\%). According to the European Association for the Study of Obesity (EASO), $23.7 \%$ of the adult population in Bulgaria is obese, $34.5 \%$ are overweight or $58.2 \%$ of people are obese or overweight. In Bulgaria, 33.2\% of the population over 20 is obese [7], which is significantly more common in males than in women $(38.8 \%$ vs. $28.3 \%, \mathrm{p}<0.001)$. With age and obesity increasing, it has grown considerably from $26 \%$ in the younger age group (20-44 years) to $38.8 \%$, respectively $39.6 \%$ in the middle and advanced age (45-59 years and 60 years). People who live in a village are significantly more obese than those living in large cities $(33.3 \%$ vs. $29.3 \%, \mathrm{p}<0.001)$.

Tasks: Specify contingent research by identifying target groups (age, gender, degrees of obesity, etc.); to carry out preliminary research; to specify the percentage of overweight and obesity; to approve the developed methodology; to process the statistics.

\section{MATERIAL AND METHODS}

The study included 21 clinically healthy middleaged women 35-45 years of age. The survey was conducted from June 2017 to November 2017 at the "Bachinovo"Research sports and recreation center, South-west University "Neofit Rilski", Blagoevgrad. After signing the informed consent statements and a preliminary medical ex- 
amination to verify the appropriate clinical picture of the subjects being studied:

1) Primary anthropometric research - anthropometric measurements with an impedance analyzer for estimating body mass parameters.

2) Anthropometric measurements to determine the somatotype profile of a contingent by Heath-Carter [8]. It consists of measuring the following variables:

- measurement of the following parameters: three skin folds (triceps skinfold, suprailiac skinfold); width of femur and humerus; arm and lower leg circumference; height and weight;

- calculating the data and obtaining a numerical coefficient for each type of somatotype;

- applying the somatogram to the values and determining the somatotype profile of the research person.

Measurements were made before and after 60 days of physical physiotherapy and cardio training. The results were processed statistically and presented graphically in GraphPad Prism 3.0.

Method of Apparatus Physiotherapy - Procedures are applied on schedule within 60 days. Each procedure has a time of action on the treated tissue, which requires a schedule of application to individual subjects within one week, with a minimum of 30 days per treatment for the cryolipolysis.

Each set of procedures is performed in accordance with the specified protocol.

- Cryolipolysis is used in the following parameters: temperature $\left(-5^{\circ} \mathrm{C}\right)$; suction power $30 \mathrm{kPa}$ and application time $60 \mathrm{~min}$. The interval between sessions is 30 days or a total of 60 days - 2 sessions.

- Cavitation is a non-invasive method that reduces fat accumulation. The $40 \mathrm{kHz}$ ultrasound waves reach and destroy the fat tissue at a depth of 1.5 to $2 \mathrm{~cm}$. Treat excess fatty deposits in the problem areas, abdomen, hips, hips or thighs to reduce cellulite. Cavitation is applied once a week or altogether 8 times for the contingent examined.

- Cardio training - 3 times a week, duration 45 minutes.

\section{RESULTS}

The results of the somotypic profile show that at the beginning of the program, the somatotype of the contingent is Mesomorphic-Endomorphic. Endomorphism is highest (6.63) and Mesomorphic (6.36) is higher than ectomorphic (1.08). Which is an indication of the presence of more fat in the body mass than normal, and also the high muscle mass values for the mesomorphic component.

After the second study, the data showed a decrease in the endomorphic index $(6,18)$, having almost equal values with the mesomorph $(6,15)$, while at the same time the greatest movement was observed in the ectomorphic index, which increased $30 \%$ to 1.38 . This indicates that the test contingent has been positively affected by the procedures and its propensity for weight loss has increased (Table 1). However, the somatotype profile remains a mesomorphendomorph.

Table 1. Results of the somatotype profile of the subjects under study.

\begin{tabular}{|c|c|c|c|c|c|c|}
\hline & \multicolumn{2}{|c|}{$\mathbf{X}$} & \multicolumn{2}{|c|}{ \pm SD } & \multicolumn{2}{|c|}{ CV \% } \\
\hline & beginning & end & beginning & end & beginning & end \\
\hline Endomorph & 6,63 & 6,18 & 1,46 & 1,42 & 21.95 & $22.93 \%$ \\
\hline Mesomorph & 6,36 & 6,15 & 1,74 & 1,67 & $27.40 \%$ & $27.16 \%$ \\
\hline Ectomorph & 1,08 & 1,38 & 1,3 & 1,38 & $120.87 \%$ & $79.46 \%$ \\
\hline Values for X & $-5,62$ & $-4,97$ & 2,54 & 2,42 & $-45.14 \%$ & $-48.74 \%$ \\
\hline Values for $\mathbf{Y}$ & 5,07 & 4,89 & 3,43 & 3,3 & $67.65 \%$ & $67.48 \%$ \\
\hline
\end{tabular}

The results we report are also confirmed by the statistical analysis of the data. As for both parameters of the somatotype profile (endo and mesomorph), a statistically significant decrease of the values was observed, with statistically significant increase in the ectomorphic (Graph 1, Fig. 1). For all three somatotype parameters, the values are statistically significant $(\mathrm{p}<0.05)$ (Wilcoxon, t-test).

Graph 1.

Comparative representation of the numerical indices of the research persons.

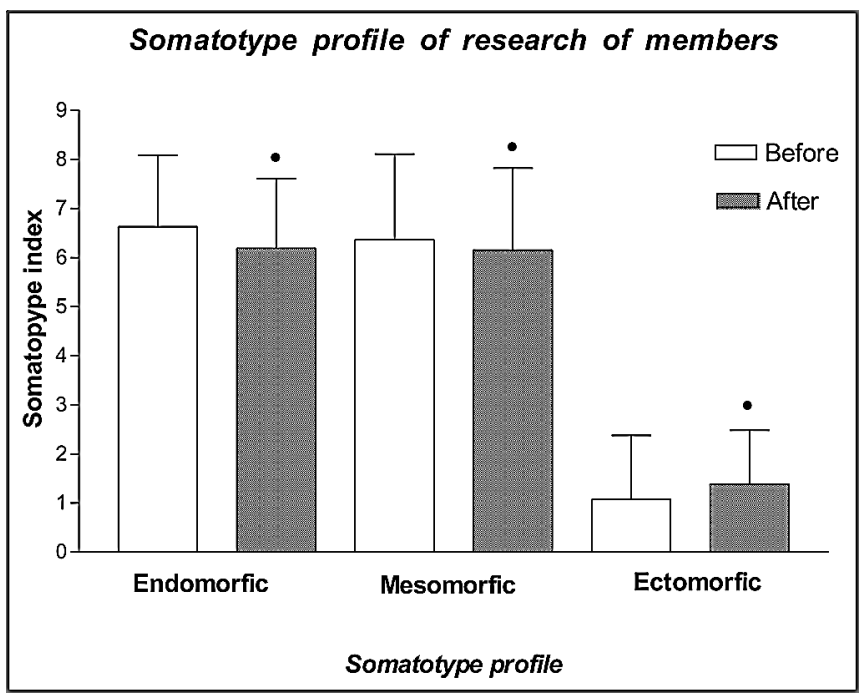


The values for the determination of the somatotype profile represented graphically by the $\mathrm{X}$ and $\mathrm{Y}$ parameters and plotted in somatochart, show a decrease in the numerical indexes and the average somatotype and shifts in a central somatotype profile of $4: 4: 4$. This corresponds to the outcome we expect. the $\mathrm{x}$ and $\mathrm{y}$ values for the contingent. $\mathrm{x}=-$ $5,62 \pm 2,54$ and $y=5,07 \pm 3,43$ (black) for starters and $x-4,97 \pm 2,42$ and $y=4,89 \pm 3,30$ (yellow) ( Fig.1).

Fig. 1. Graphical representation of the $\mathrm{x}$ and $\mathrm{y}$ values for the contingent.

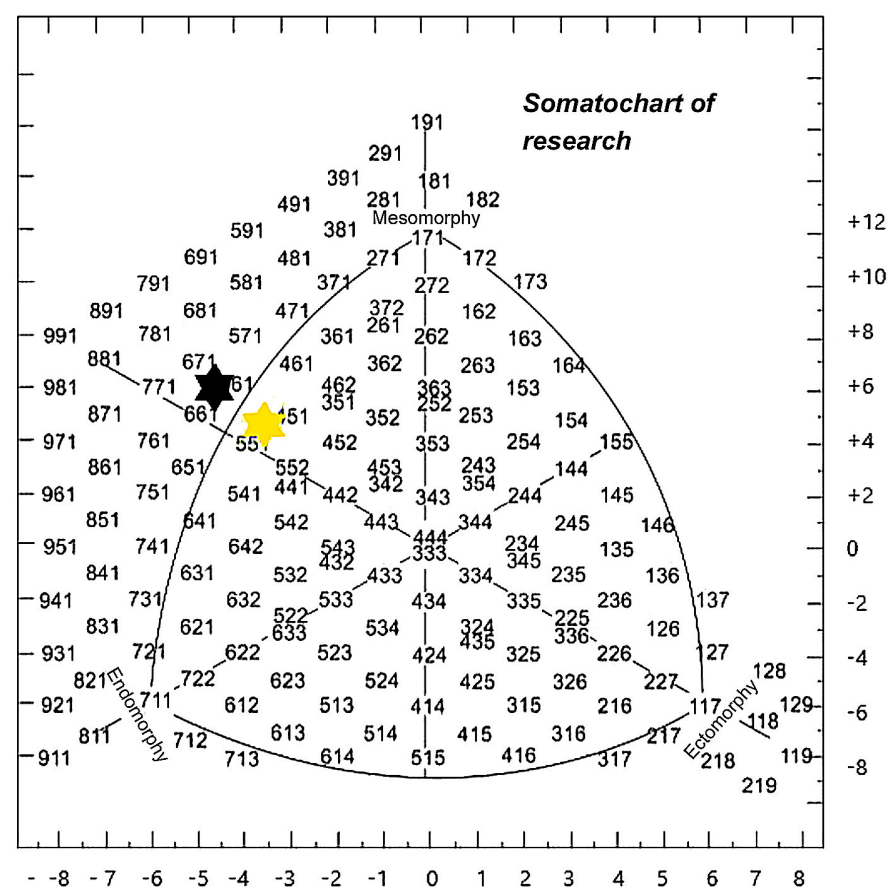

Results of skin fold study after cryolipolysis, cavitation, and cardio training procedures. They show a statistically significant decrease in measured skin folds; biceps, suprailiac, subscapular, and triceps. Measurement of subcutaneous fat by the skin thickness indexing method is informative for certain body segments, but it is also an indirect indicator of total fat reduction. Data are processed statistically and statistically, are shown graphically in

Graph 2, by a nonparametric statistical method for Wilcoxon dependent samples, a t-test at $(\mathrm{p}<0.05)$, and a statistically significant decrease in the four measured skin folds.

Graph 2. The statistically significant difference in the values $(p<0.05)$ of the measured skin folds at the beginning and end of the applied methodology (Wilcoxon, t-test).

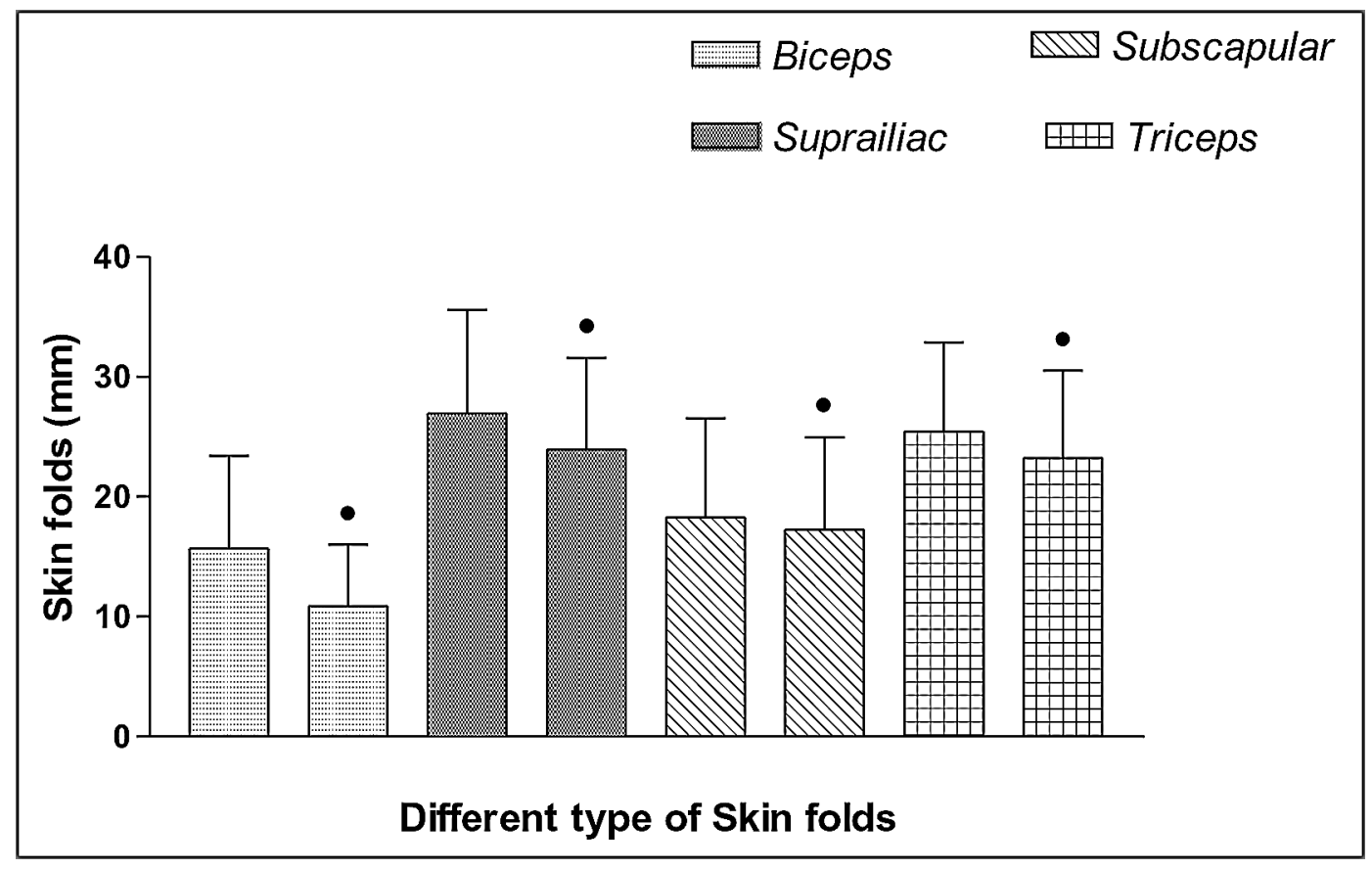


Segment analysis of body composition measured with the bioimpedance presented in Graphs 3 and 4.

From the body composition data obtained, only the BMI $(\mathrm{kg} / \mathrm{m} 2), \mathrm{VFA}(\mathrm{cm} 2)$ and $\mathrm{MBF}(\mathrm{kg})$ have a statistically significant reduction in the values. Statistically significant difference $(\mathrm{p}<0.05)$ for BMI values (Wilcoxon, t-test).

Graphs 3. Graphical representation of the data for the analyzed parameters from the segment analysis.

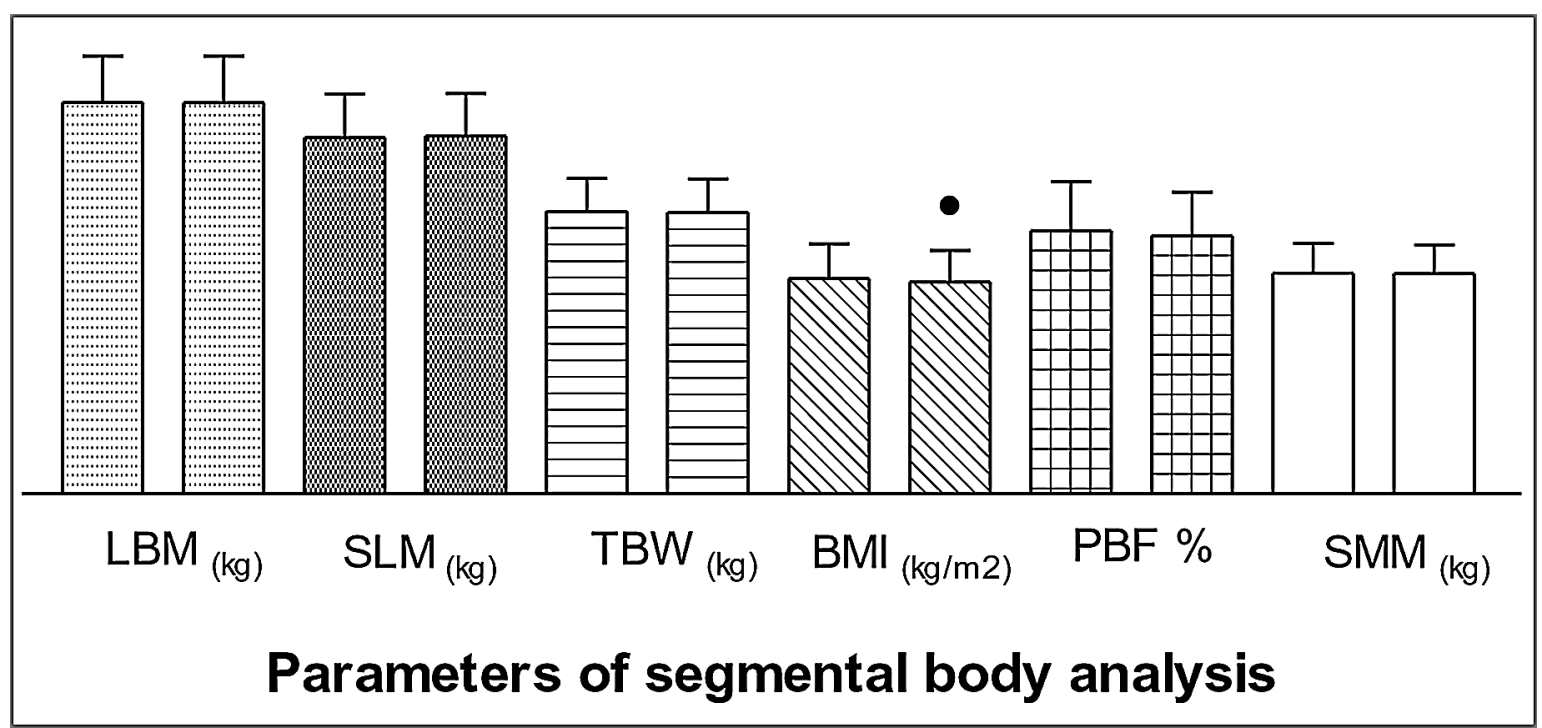

A similar trend was observed with $\operatorname{MBF}(\mathrm{kg})$, which is an indicator of the presence of fat mass, measured in kilograms, and there is a statistically significant decrease in the values of the subjects studied. Similar are the results for the $\mathrm{AC}(\mathrm{cm})$ abdominal circumference and fat mass $(\mathrm{kg})$. It turns out that the reduction of fat mass leads to a decrease in the parameters that are directly or indirectly dependent on it. We assume that this is due to our method of reduction of fat, by physical physiotherapy and cardio training. Statistically significant difference $(\mathrm{p}<0.05)$ for VFA and MBF (Wilcoxon, t-test).

Graphs 4. Graphical representation of the data from the analyzed parameters from the segment analysis.

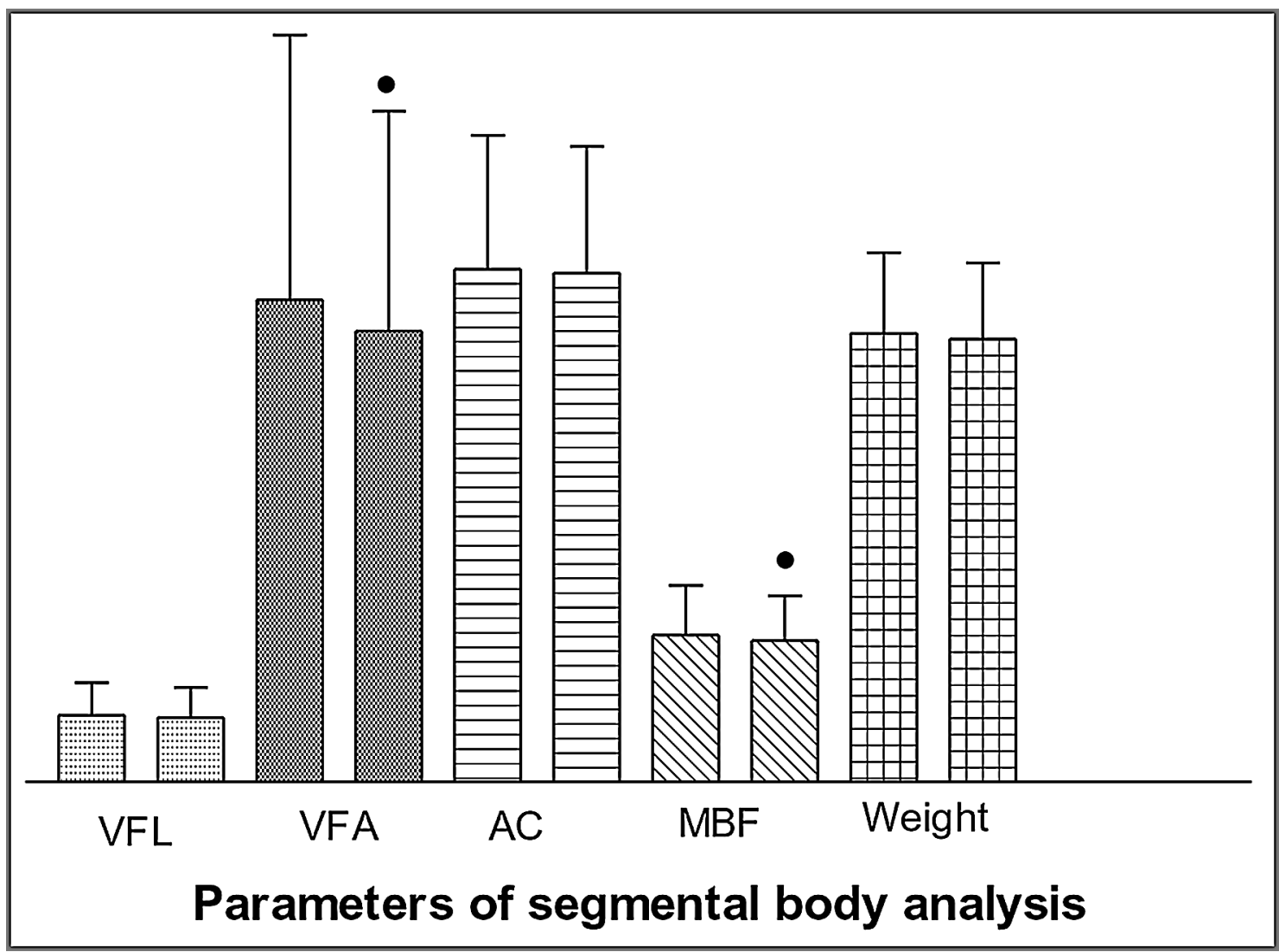


From the body composition data obtained, only the $\boldsymbol{B M I}(\mathbf{k g} / \mathbf{m} 2), \boldsymbol{V F A}(\mathbf{c m} 2)$ and $\boldsymbol{M B F}(\boldsymbol{k g})$ have a statistically significant reduction in the values.

A similar trend was observed with $\boldsymbol{M B F}(\mathbf{k g})$, which is an indicator of the presence of fat mass, measured in kilograms, and there is a statistically significant decrease in the values of the subjects studied. Similar are the results for the $\boldsymbol{A C}(\mathbf{c m})$ abdominal circumference and fat mass $(\mathrm{kg})$. It turns out that the reduction of fat mass leads to a decrease in the parameters that are directly or indirectly dependent on it. We assume that this is due to our method of reduction of fat, by physical physiotherapy and cardio training.

A reliable difference in the values of the measured parameters before and after the applied $\mathrm{P}$-value $<0.0001$ (Wilcoxon, t-test) is observed, with no statistically significant changes being observed in the hips circumference in Pvalue $<0.05$ level (Wilcoxon, $t$-test). The results are presented in Graph 5.

Graph 5. Comparative representation of the numerical indices of the surveyed persons.

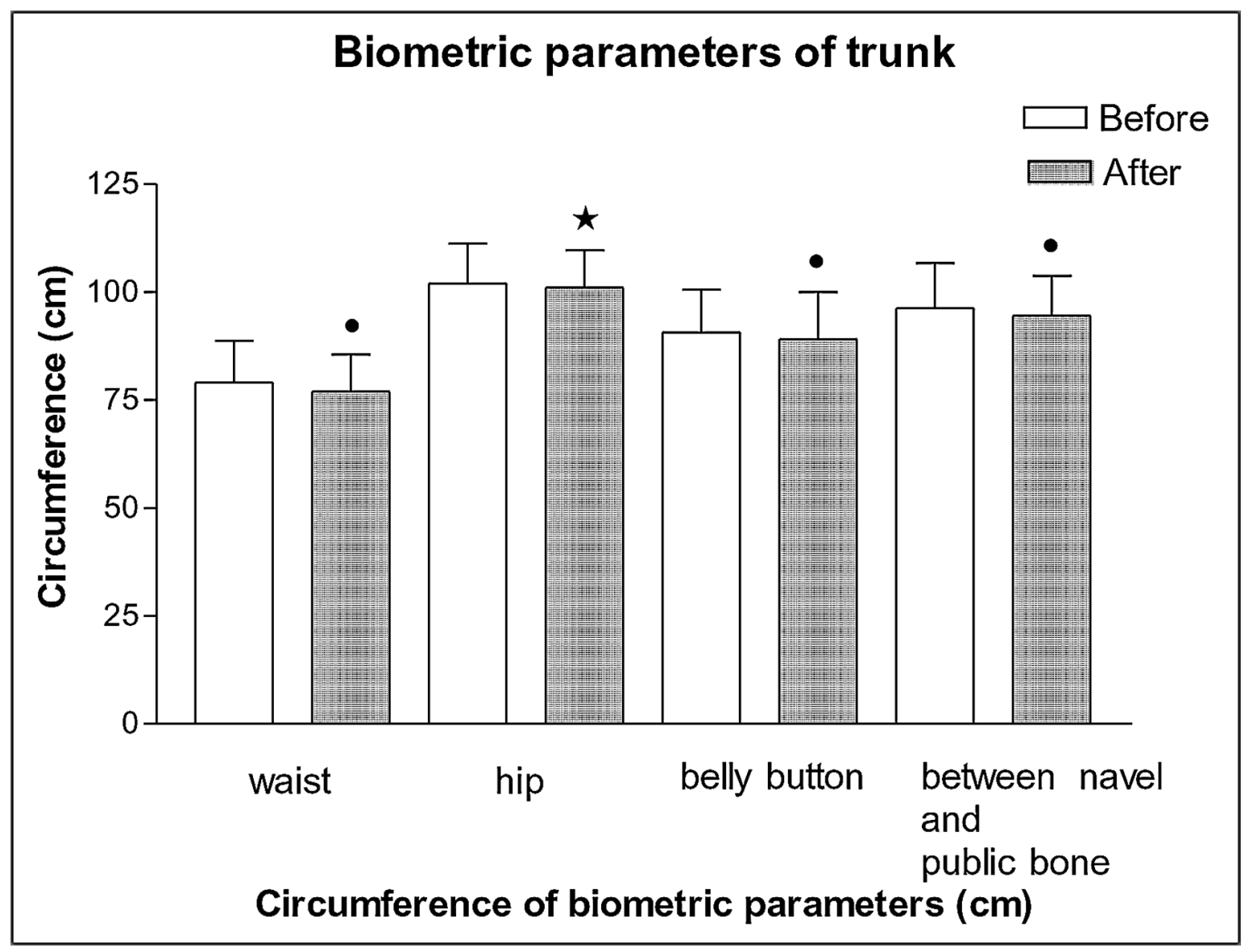

A statistically significant decrease in the circumference of both thighs was observed, at the measured 8, 20 and $28 \mathrm{~cm}$ patella heights, P-value $<0.0001$ level (Wilcoxon, t-test). The results are presented in Graph 6 and Graph 7 . A significant difference (decrease) between data of measuring in both of upper legs, before and after the procedure at the P-value $<0.0001$ level (Wilcoxon, t-test). 
Graph 6. Comparison of the results $(\mathrm{cm})$ of the variation values in the right thigh circumferences at different lengths.

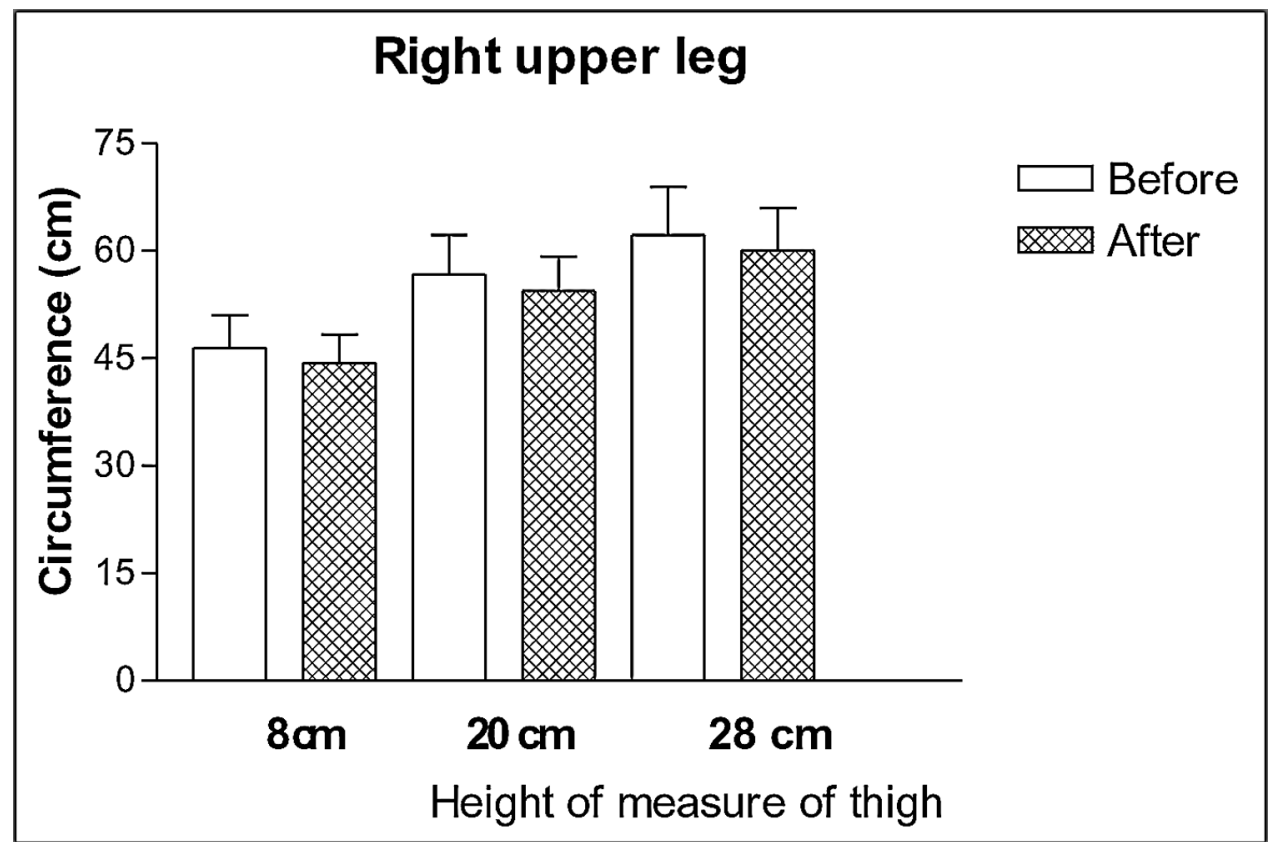

Graph 7. Comparison of the results $(\mathrm{cm})$ of the variation values in the left thigh circumferences at different lengths.

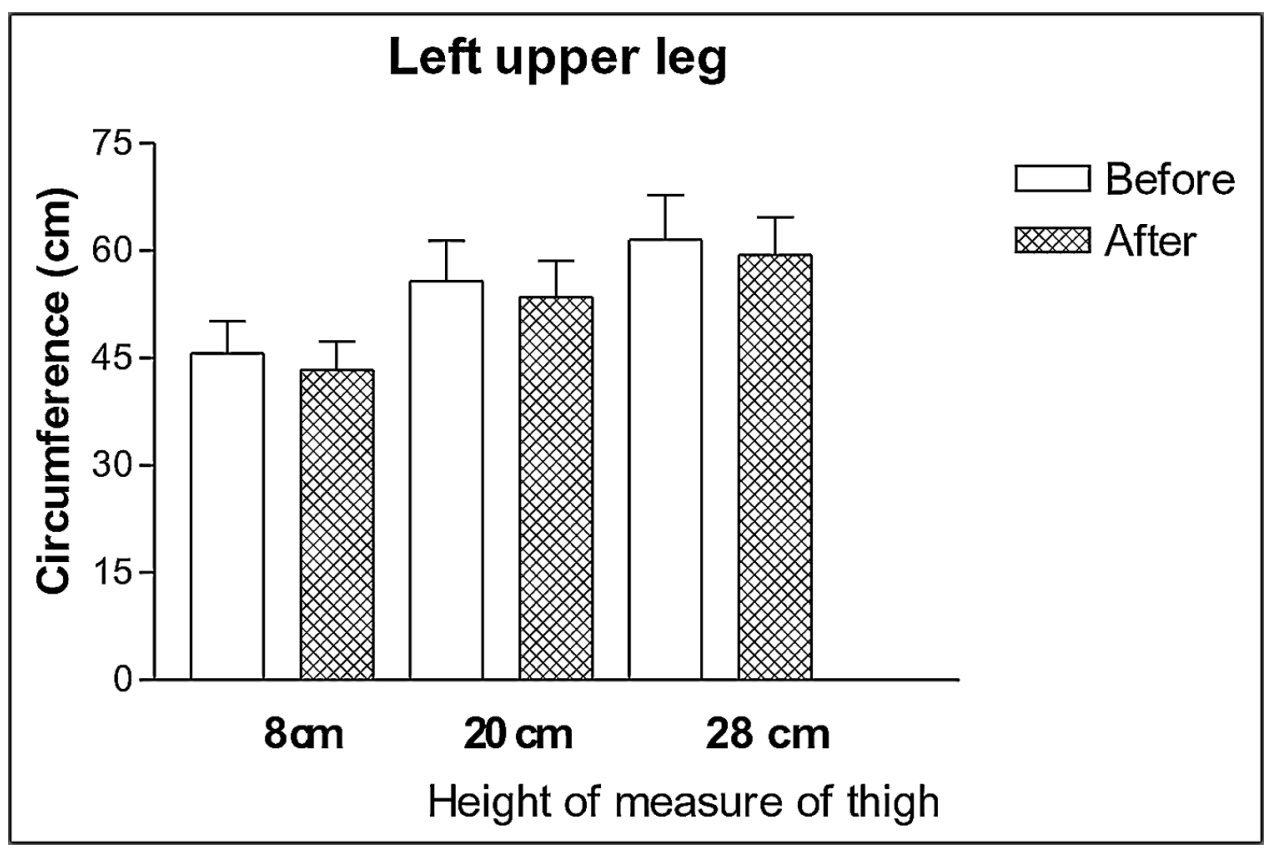

\section{DISCUSSION}

Our results show that there is a reduction in body fat in the studied contingent following a screening procedure involving cryolipolysis, cavitation and cardio treatment within 60 days. Our results are similar to those of [7, $8,9]$ of 3,111 studies identified in our reviews, 13 studies assessed lipolysis, 10 cryolipolysis and 8 considered radiofrequency. Nine studies with the same follow-up duration in three different outcome group were included in the meta-analysis. Radiofrequency showed an overall pooled estimate of $2.7 \mathrm{~cm}$ (95\% CI; 2.3-3.1) of mean reduction in circumference of the abdomen after the inter- vention. The pooled estimate of the reduction in fat layer thickness was 78\% (95\% CI; 73\%-83\%) after Lipolysis and a pooled estimate of weight loss was $3.01 \mathrm{~kg}$ (95\% CI; 2.3 3.6) after liposuction. The cost analysis revealed no significant differences between the costs of these interventions.

\section{CONCLUSION}

The approbation methodology with non-invasive interventions for reduction of body fat has a positive effect on the research contingents and leads to the modeling of the body. 


\title{
Acknowledgements:
}

This article is supported under Project No. RP-A2/17, Project topic: Approbation of methods for reduction of body fat through apparatus physiotherapy.

\section{REFERENCES:}

1.Elagizi A, Kachur S, Lavie CJ, Carbone S, Pandey A, Ortega FB, et al. An Overview and Update on Obesity and the Obesity Paradox in Cardiovascular Diseases. Prog Cardiovasc Dis. 2018 Jul-Aug;61(2):142-150. [PubMed] [Crossref]

2. Goodarzi MO. Genetics of obesity: what genetic association studies have taught us about the biology of obesity and its complications. Lancet Diabetes Endocrinol. 2018 Mar;6(3): 223-236. [PubMed] [Crossref]

3. Oktay AA, Lavie CJ, Kokkinos PF, Parto P, Pandey A, Ventura HO. The Interaction of Cardiorespiratory Fitness With Obesity and the Obesity Paradox in Cardiovascular Disease. Prog Cardiovasc Dis. 2017 Jun-Jul; 60(1):30-44. [PubMed] [Crossref]
4. Whitlock G, Lewington $S$, Sherliker P, Clarke R, Emberson J, Halsey $\mathrm{J}$, et al. Body-mass index and cause-specific mortality in 900000 adults: collaborative analyses of 57 prospective studies. Lancet. 2009 Mar 28;373(9669):1083-96. [PubMed] [Crossref]

5. Pischon T, Boeing H, Hoffmann K, Bergmann M, Schulze MB, Overvad $\mathrm{K}$, et al. General and abdominal adiposity and risk of death in Europe. $N$ Engl J Med. 2008 Nov;359(20):210520. [PubMed] [Crossref]

6. Loscalzo J, Fauci AS, Braunwald E, Dennis LK, Hauser SL, Longo DL. Harrison's principles of internal medicine. McGraw-HillMedical. 2008.
7. Borisova AM. [Epidemiology of Endocrine Diseases in Bulgaria.] [in Bulgarian] Paradigma Publishing House, Sofia. 2012.

8. Nojomi M, Moradi-Lakeh M, Velayati A, Naghibzadeh-Tahami A, Dadgostar H, Ghorabi G, et al. Health technology assessment of non-invasive interventions for weight loss and body shape in Iran. Med J Islam Repub Iran. 2016 Apr 3;30:348. [PubMed]

9. Faulhaber J, Sandhofer M, Weiss C, Sattler G, Sadick NS. Effective noninvasive body contouring by using a combination of cryolipolysis, injection lipolysis, and shock waves. $J$ Cosmet Dermatol. 2019 Aug;18(4): 1014-1019. [PubMed] [ Crossref]

Please cite this article as: Gramatikova M, Mitova S, Kanelov I. Approbating methodology for reduction of body fat with cryolipolysis and cavitation. J of IMAB. 2020 Oct-Dec;26(4):3416-3422.

DOI: https://doi.org/10.5272/jimab.2020264.3416

Received: 24/09/2019; Published online: 06/10/2020

\author{
Address for correspondence: \\ Assoc. Prof. Mariya Gramatikova, PhD \\ Department of Kinesitherapy, \\ Faculty of Public Health, Healthcare and Sports, \\ South-West University Neofit Rilski \\ 66 Ivan Mihaylov, 2700 Blagoevgrad, Bulgaria. \\ E-mail: mari_gramatikova@abv.bg
}

